\title{
Seroepidemiology and molecular diversity of Leishmania donovani complex in Georgia
}

\section{(a) CrossMark}

\author{
Giorgi Babuadze ${ }^{1,2^{*}}$, Jason Farlow ${ }^{3}$, Harry P. de Koning ${ }^{4}$, Eugenia Carrillo ${ }^{5}$, Giorgi Chakhunashvili ${ }^{1}$, \\ Mari Murskvaladze ${ }^{2}$, Merab Kekelidze $^{1}$, Irakli Karseladze ${ }^{1}$, Nora Kokaia ${ }^{6}$, Irine Kalandadze', David Tsereteli ${ }^{1}$, \\ Ivane Markhvashvili', Ketevan Sidamonidze ${ }^{1}$, Gvantsa Chanturia' ${ }^{1}$, Ekaterine Adeishvili ${ }^{1}$ and Paata Imnadze ${ }^{1}$
}

\begin{abstract}
Background: Leishmaniasis includes multiple clinical syndromes, most notably visceral, cutaneous, and mucosal forms. Visceral leishmaniasis $(\mathrm{VL})$, also known as kala-azar, is a potentially fatal disease endemic to large parts of Africa and Asia, and in South-Eastern Europe (Greece, Turkey, Georgia). Visceral leishmaniasis is a parasitic zoonosis caused by species of the $L$. donovani complex. In the classical epidemiological model the main reservoir for $V L$ are canines.

Methods: The study included a cohort of 513 individuals of both genders (190 males and 323 females) from the ages of 1 to 70 years that were screened in ten villages across two districts in Kakheti using the Kalazar Detect ${ }^{\mathrm{TM}}$ rK39 rapid diagnostic test. The phylogenetic diversity patterns of local strains, based on the rDNA internal transcribed spacer (ITS) sequences, were assessed for samples obtained from patients with suspected L. donovani infection, from canine reservoirs and from Phlebotomus sand flies obtained from different geographical areas of Georgia and from Azerbaijan.
\end{abstract}

Results: Out of a total of 600 domestic dog blood samples 95 (15.8\%) were positive by rK39 rapid diagnostic tests. For symptomatic domestic dogs, the testing of conjunctival swabs or bone marrow aspirates revealed a higher VL incidence in Kvareli District (Kvareli; $19.4 \%, n=329$ ) compared with that observed for Sagarejo District (Sagarejo; $11.4 \%, n=271$ ). A total of 231 sand flies of both genders were collected during the 2-month period; of the 114 females, $1.75 \%$ were PCR positive for the presence of Leishmania spp.

Conclusions: VL infection rates remain high in both canines and humans in Georgia, with disease in several known natural foci. The genetic relationships derived from rDNA internal transcribed spacer (ITS) sequence comparisons identified genetic subgroups, revealing preliminary insights into the genetic structure of $L$. donovani complex members currently circulating in the South Caucasus and demonstrates the utility of ITS-based genotyping in the resource-limited country of Georgia.

Keywords: Epidemiology, Visceral leishmaniasis, Phylogeny of Leishmania, ITS Sequencing, Georgia, Phlebotomus

\section{Background}

Leishmaniasis is a complex of diseases caused by intracellular parasitic protozoans of the genus Leishmania, a representative of the order Kinetoplastida, family Trypanosomatidae. The two most common manifestations of the disease are the cutaneous form, which is largely self-healing but often

\footnotetext{
* Correspondence: gbabuadze@ncdc.ge

${ }^{1}$ National Center for Disease Control and Public Health of Georgia, 9 M.

Asatiani Str. 0186, Tbilisi, Georgia

${ }^{2}$ Ilia State University, Tbilisi, Georgia

Full list of author information is available at the end of the article
}

leaves disfiguring scars, and the usually fatal visceral form. Estimated cases of visceral leishmaniasis (VL) have reached 300,000 globally [1], with a high rate of HIV co-infections, and over 20,000-40,000 deaths annually [2, 3]. In addition, a high incidence of canine viscerocutaneous leishmaniasis, as well as an increasing burden of human VL, is observed throughout European Mediterranean and East European countries $[2,4]$ and is spreading into central Europe $[5,6]$. The genus Leishmania is currently divided into several species complexes. Numerous Leishmania species have been reported in Eurasia and Africa, including L. infantum, $L$. 
major, $L$. donovani, $L$. tropica, $L$. aethiopica, $L$. turanica, $L$. gerbilli, and L. arabica [7]. L. infantum/chagasi and $L$. donovani cause VL with some minor differences, for which various species of canids, in particular, serve as the animal reservoir, although in India/Nepal/Bangladesh VL is considered as principally antroponotic [2].

VL presents one of the most serious public health concerns in Georgia [8,9]. The first known outbreak of VL in Georgia, in 1913, occurred in the eastern-most part of the country (Kakheti region) and gave rise to the first clinical report of this disease in the Caucasus region. In 1954 a survey found 540 cases in eastern Georgia [10]: cases were registered in six cities and 164 villages, mainly in the Kakheti region in the east of the country, but also in the more central region of Shida Kartli [11] (see map in Fig. 1a). In the 1960s large scale malaria control efforts were carried out in eastern Georgia using massive spraying campaigns with dichlorodiphenyltrichloroethane (DDT) [11], which significantly reduced the local sand fly population in addition to the intended targets, the Anopheles mosquitoes spreading malaria. This historical spraying campaign is now generally considered to be the primary cause of the reduction in reported VL cases over the subsequent 40 years. As a consequence, however, there has been an almost complete lack of biosurveillance in eastern Georgia for four decades, and therefore there are no reliable data on clinical and sub-clinical prevalence of leishmaniasis in the region for this period.

Historically, isoenzyme analysis has been the gold standard for Leishmania species and strain identification and discrimination. Due to the propensity for artefactual outcomes derived from this method, molecular assays have largely replaced isoenzyme-based assays for this purpose. Several molecular typing techniques have shown utility in distinguishing individual species of Leishmania, including random amplification of polymorphic DNA (RAPD) [12], amplified fragment length polymorphism (AFLP) [13, 14], kinetoplastid DNA (kDNA) PCR-based restriction fragment length polymorphism (RFLP) [15], microsatellite sequencing [12], and SCAR (sequence-confirmed amplified region) analysis [16]. In addition, ribosomal internal transcribed spacer (ITS) sequences have previously characterized
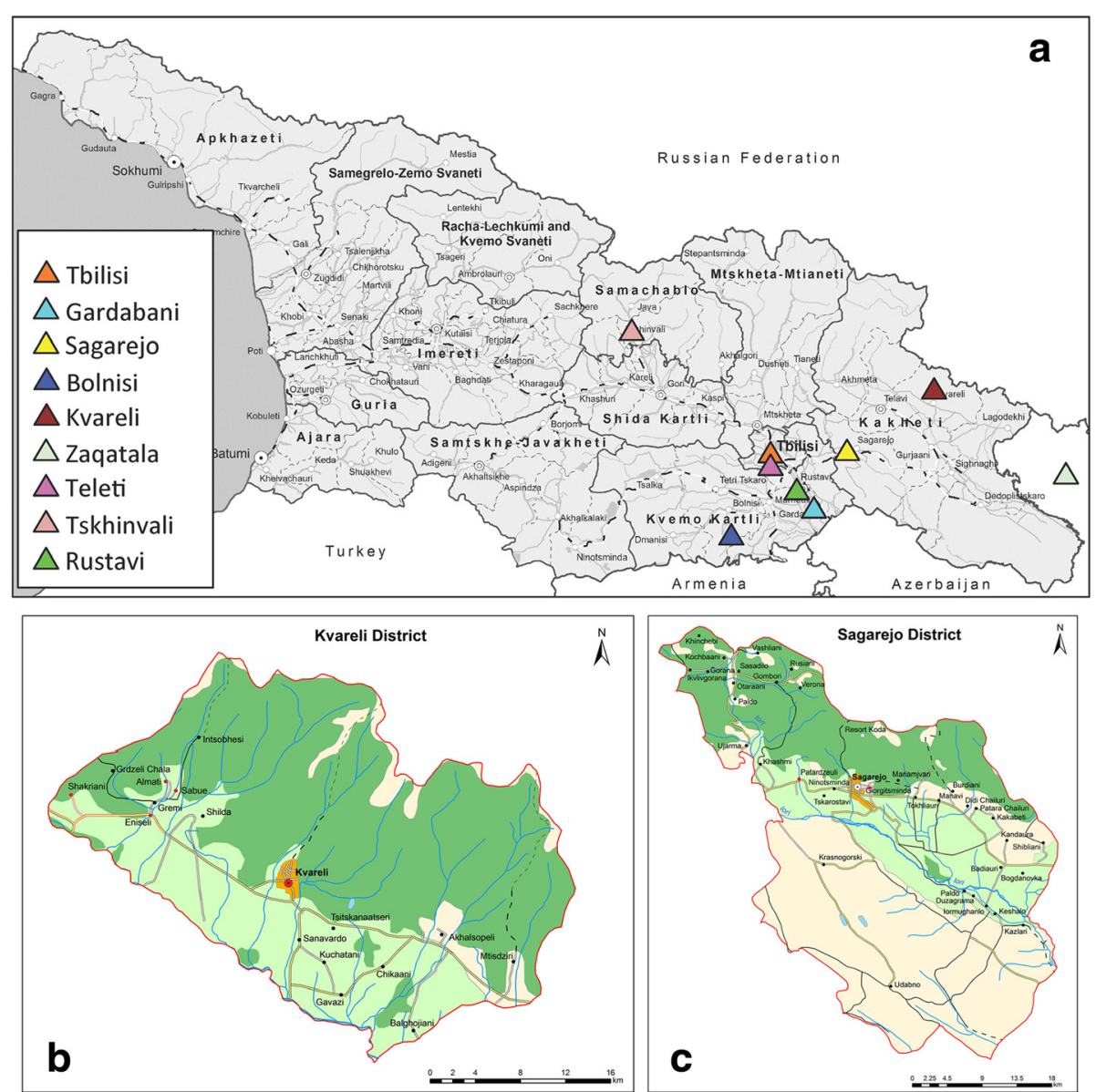

Fig. 1 Map of Georgia and detailed maps of the study areas. a Map of Georgia. b Map of Kvareli District. c Map of Sagarejo District. The red spots indicate the villages where rk39 test- positives were found 
genetic relationships within the Leishmania, providing key information about leishmaniasis distribution and population structure [12-14].

We report here the seroepidemiology and genotyping of VL foci in the eastern half of Georgia. Limited resources are available in this country and we present the first report of Leishmania strain detection and genotyping in Georgia. Phylogenetic analysis of ITS-based Georgian VL samples, collected over a 2-year period, revealed preliminary insights into the genetic structure of $L$. donovani complex members currently circulating in Georgia. This has identified new genotypes that are unique to Georgia, has provided much-needed insights into the spread of leishmaniasis in the south Caucasus region, and informs rational intervention strategies needed to curb the resurgent VL epidemic in the region. In addition, it demonstrates the utility of ITS-based genotyping in resource-limited settings.

\section{Methods}

In order to obtain data on VL prevalence and disease burden within the human population and the canine reservoir, seroepidemiological surveys were performed in two historically active VL foci in the Kakheti region: Kvareli and Sagarejo districts (Fig. 1b and c). Infection screening was performed on domestic dogs in the selected districts, using the Kalazar Detect ${ }^{\text {Tm }}$ rK39 rapid diagnostic test (rK39). Collection and taxonomic identification of sand fly species as potential Leishmania vectors was performed and the presence of Leishmania organisms was confirmed using microscopy and PCR. Amplification and sequencing of the ITS region of 19 isolates allowed the molecular genotyping necessary to identify the geographical spread of unique strains, and their comparisons with strains that have previously been reported from other regions.

\section{Study area}

Georgia is located on the crossroads of Europe and Asia. It lays at the eastern end of the Black Sea, with Turkey and Armenia to the south, Azerbaijan to the east and Russia to the north, across the Caucasus Mountains. The capital and largest city is Tbilisi. Georgia's total territory covers $69,700 \mathrm{~km}^{2}$. Georgia is divided into nine regions and two autonomous republics (Fig. 1a). These, in turn, are subdivided into 69 districts.

Kakheti is a region in eastern Georgia. The region comprises of eight administrative districts: Telavi, Gurjaani, Kvareli, Sagarejo, Dedoplistsqaro, Signagi, Lagodekhi and Akhmeta. Kakheti is bordered by the Russian Federation to the north-east, Azerbaijan to the south-east, and the Georgian regions of Mtskheta-Mtianeti and Kvemo Kartli to the west (Fig. 1a). Two of the above listed districts of Kakheti region were chosen for this study: Kvareli and Sagarejo. Our attention was drawn to these areas in particular because of a significantly increased number of VL cases since 2009, up from at most sporadic registered cases to 4-9 clinical cases in each district annually, making those two districts among the most affected with VL infection in the Kakheti region [official disease records, National Centre for Disease Control (NCDC), Tbilisi, Georgia].

Kvareli District is a municipal district and administrativeterritorial unit in East Georgia, of mostly agricultural lands and forest, $133 \mathrm{~km}$ from Tbilisi, in the north-eastern part of the Kakheti region at $41.9514{ }^{\circ} \mathrm{N}, 45.8017^{\circ} \mathrm{E}$. The terrain of Kvareli district $\left(1001 \mathrm{~km}^{2}\right)$ is diverse and lies at an elevation of 255-1800 m, with 40,200 inhabitants (census 2012), near the foothills of the Greater Caucasus Mountains. Sagarejo District is situated $58 \mathrm{~km}$ to the east of Tbilisi, and has a population of 59,212 (2002 census). The district is situated at an elevation of $460-1800 \mathrm{~m}$, with an area of $1491 \mathrm{~km}^{2}$, containing forests, vineyards and a large segment of desertlike terrain. Apart from the desert part of Sagarejo District, the climate of the two study areas is very similar, with hot summers creating the conditions for breeding of Phlebotomus sand flies.

\section{Ethics statement}

Ethical clearance for conducting this study was granted by the Institutional Board of Review of the National Center for Disease Control and Public Health (IRB00002150) in compliance with Georgian legislation and international bioethical frameworks. All volunteers were interviewed and written informed consent was obtained for participation in the study. Under the current state regulations no special permission was required for the research and diagnostic procedures utilized for the pet animal work in this study. However written informed consent was obtained from the particular pet owners.

Investigators and animal care staff had appropriate qualifications and experience for conducting the procedures described below on living animals. Each animal received compassionate care, comfort, and protection from abuse and unnecessary pain. In order to obtain the bone marrow aspirates, a mixture of $2 \%$ Xylazine $(1-2 \mathrm{mg} / \mathrm{kg})$ and $5 \%$ Kaipsol $(5-10 \mathrm{mg} / \mathrm{kg})$ was used for anesthesia and myorelaxation. Investigators minimized distress in individual animals or populations of animals in accordance with the European Convention for the Protection of Vertebrate Animals Used for Experimental and Other Scientific Purposes, Strasbourg 1986.

\section{Study design and sampling}

A. Human subjects For the selection of human subjects, a survey was performed in households in the district, starting with households from which a clinical case 
of VL had been reported, preferentially a person aged 0 14. ('new' cases as opposed to historical cases). Among 175 households, 513 human subjects (190 males and 323 females) from 1 to 70 years (average $=24.2$; median $=23$ ) were enrolled from ten villages of the two Kakheti districts. Serum samples were obtained from all 513 individuals over a 2-month period from June to July 2014. One of the objectives of the study was to determine the transmission risk-factors in the Kakheti region districts where confirmed VL cases have increased in the last ten years. For this purpose, we included the following criteria for the enrolment of study subjects: (i) human subjects were a member of a household where confirmed cases were registered since 2009; or (ii) subjects would reside close to a previously reported case. Additionally, it was decided that no more than three human samples (and a maximum of five samples including dogs and vectors) were to be collected per household in order to avoid sample bias. In both districts, virtually all (> $95 \%$ ) households have at least one dog, especially in the outlying villages. Human blood samples were collected in Vacutainer vials designed for serum and stored at $4{ }^{\circ} \mathrm{C}$. During this survey a total of seven rK39 test-positive persons were identified, who were referred to the Institute of Medical Parasitology and Tropical Medicine in Tbilisi, for confirmatory tests on bone marrow aspirates. PCR testing of bone marrow samples, provided by the Institute of Medical Parasitology and Tropical Medicine, was performed at the R. Lugar Center, Tbilisi.

B. Canine and vector sampling A total of 600 asymptomatic dog samples (blood and serum) were obtained during the three month period June-August, 2014 in both districts ( $n=329$, Kvareli District and $n=271$, Sagarejo District). Dog sampling was implemented in the same settlements where human subject and vector survey samples were collected. Canine blood samples were stored and tested under similar conditions as the human samples. Vector surveys were simultaneously implemented in Kvareli and Sagarejo districts (July-August, 2014), using seven standard CDC light traps [17]. For each VL focus the light traps were set between $7 \mathrm{pm}$ and $7 \mathrm{am}$ on four consecutive nights per week. Sand fly species was determined according to the morphological ID keys and scored according to blood fed versus unfed [18]. A total of 114 of the 231 sand flies collected were female ( $n=162$, Kvareli and $n=69$, Sagarejo District). For detection of Leishmania parasites all female sand flies were placed in $1 \times$ sterile PBS buffer and stored at $4{ }^{\circ} \mathrm{C}$ for further PCR testing.

\section{rK39 testing}

For the detection of VL antibodies in human and dog serum samples Kalazar Detect ${ }^{\text {mix }}$ rK39 Rapid tests (InBios International Inc, Seattle, USA) were performed according to the manufacturer's instructions. A total of $20 \mathrm{ml}$ was collected for each human serum sample. The test was assumed positive when a control line and test line appeared on the dipstick within $10 \mathrm{~min}$, and negative if only a single control line appeared $[19,20]$.

\section{Culture}

Culture tubes containing Novy-MacNeal-Nicolle (NNN medium) agar with $10 \%$ defibrinated rabbit blood were overlaid with $200 \mu \mathrm{l}$ of complete RPMI medium containing $20 \%$ fetal bovine serum. Several drops of human bone marrow and canine spleen aspirates (collected in EDTA tubes from Becton, Dickinson and Company, USA) were introduced into the tubes containing NNN agar and RPMI medium. For sand fly samples, mid guts were extracted and diluted in two drops of sterile PBS buffer, which was finally transferred to NNN medium with a 2-ml syringe. The tubes were incubated at $27^{\circ} \mathrm{C}$; and were examined by light microscopy two times per week until promastigotes were noted or several weeks had passed. The two cultures thus obtained (one from a canine spleen aspirate and another from a phlebotomine sand fly) were transferred from tubes to small flasks containing $10 \mathrm{ml}$ of fresh RPMI medium in order to obtain large numbers of parasites for further investigations. Cultures were passaged several times. Once the parasites reached log phase, liquid culture medium was harvested from the flasks and centrifuged at $1000 \times \mathrm{g}$ for $10 \mathrm{~min}$. Supernatants were discarded and pellets washed in $50 \mathrm{ml}$ of $1 \%$ Hank's + D-Glucose medium (pH 7.2) prior to DNA extraction.

\section{DNA extraction and PCR amplification}

DNA was extracted using the QIAamp DNA Mini Kit (Qiagen) according to the manufacturer's instructions. A total of 19 isolates were used for phylogenetic analysis in this study. One of the isolates obtained was from a patient from the Azerbaijani village Zakatala, who had been referred to the Institute of Medical Parasitology, Tbilisi, Georgia, for confirmatory test and further treatment.

Sources, designation and geographical origins of the samples used in this study are listed in Tables 1 and 2 . For the initial evaluations of the Leishmania ITS region, the $1030 \mathrm{bp}$ ribosomal ITS region was amplified and sequenced using Leishmania-specific primers: LITSR $\left(5^{\prime}\right.$ CTG GAT CAT TTT CCG ATG - 3') and LITSV (5'ACA CTC AGG TCG TAA AC - 3') [14]. Separately were amplified ITS1 - LITSR ( $5^{\prime}$ - CTG GAT CAT TTT CCG ATG - 3')/L5.8S (5' - TGA TAC CAC TTA TCG CAC TT- $\left.3^{\prime}\right)$, ITS2 - L5.8SR (5' - AAG TGC GAT AAG TGG TA - 3')/ LITSV (5' - ACA CTC AGG TCG TAA AC - 3') [14] and ITS2 generic primers - LGITS2F2 (5' - GCA TGC CAT ATT CTC AGT GTC - 3')/LGITS2R2 (5' - GGC CAA CGC GAA GTT GAA TTC - 3') [21]. 
Table 1 Sample description of Georgian sequences used in this study

\begin{tabular}{|c|c|c|c|c|c|c|}
\hline Origin & Type & Geographical location & Year & ITS sequence type & Accession number & Clinical presentation \\
\hline Human & DNA & Gardabani & 2013 & ITS1/2 & MM201501 & Yes \\
\hline Human & DNA & Tkhinvali & 2014 & ITS1/2 & MM201502 & Yes \\
\hline Human & DNA & Bolnisi & 2014 & ITS1/2 & MM201503 & Yes \\
\hline Canine & DNA & Kvareli & 2014 & ITS1/2 & MM201504 & no \\
\hline Canine & DNA & Sagarejo & 2014 & ITS1/2 & MM201505 & No \\
\hline Canine & DNA & Sagarejo & 2014 & ITS1/2 & MM201506 & No \\
\hline Human & DNA & Rustavi & 2014 & ITS1/2 & MM201507 & yes \\
\hline Canine & DNA & Sagarejo & 2014 & ITS1/2 & MM201508 & Yes \\
\hline Canine & Culture & Tbilisi & 2014 & ITS1/2 & MM201509 & Yes \\
\hline Canine & DNA & Tbilisi & 2012 & ITS1/2 & MM201511 & No \\
\hline Canine & DNA & Tbilisi & 2012 & ITS1/2 & MM201512 & No \\
\hline Canine & DNA & Tbilisi & 2012 & ITS1/2 & MM201513 & No \\
\hline Canine & DNA & Tbilisi & 2012 & ITS1/2 & MM201514 & No \\
\hline Human & DNA & Tbilisi & 2012 & ITS1/2 & MM201515 & No \\
\hline P. balcanicus & DNA & Tbilisi & 2012 & ITS1/2 & MM201516 & \\
\hline P. balcanicus & DNA & Tbilisi & 2012 & ITS1/2 & MM201517 & \\
\hline Human & DNA & Zakatala & 2014 & ITS1/2 & MM201519 & Yes \\
\hline Canine & DNA & Tbilisi & 2013 & ITS1/2 & MM2015120 & No \\
\hline Canine & DNA & Teleti & 2013 & ITS1/2 & MM2015121 & No \\
\hline
\end{tabular}

For the PCR amplification, 3-10 ng of DNA was added into a mix containing $10 \times$ reaction buffer, $0.2 \mathrm{mM}$ dNTP's, $0.2 \mu \mathrm{M}$ of each primer, nuclease-free distilled water (Sigma-Aldrich) and 2 units of Taq polymerase (Biotools). PCR was performed in a thermocycler TC5000 (TECHNE), using the following cycle parameters: $94{ }^{\circ} \mathrm{C}$ for $2 \mathrm{~min}$, followed by 40 cycles of $94{ }^{\circ} \mathrm{C}$ for $30 \mathrm{~s}$, $55{ }^{\circ} \mathrm{C}$ for $30 \mathrm{~s}, 70{ }^{\circ} \mathrm{C}$ for $1 \mathrm{~min}$, and a final extension of $72{ }^{\circ} \mathrm{C}$ for $10 \mathrm{~min}$. The amplicons were purified by precipitation, first with ice-cold $100 \%$ and then $70 \% 2$ Propanol. Sequencing reactions of the amplicons were carried out with the BigDye Terminator Kit, version 3.1 (Applied Biosystems). For further steps sequencing reaction mixtures were purified by again washing with $100 \%$ and $70 \%$ 2-Propanol. The purified product was transferred into Applied Biosystems ABI PRISM 96-Well optical reaction plates; to each well $10 \mu \mathrm{l} \mathrm{Hi-}$ Di formamide (Thermo Fisher) was added. Subsequently products were denatured at $94{ }^{\circ} \mathrm{C}$ for $2 \mathrm{~min}$ in a thermal cycler and finally analyzed on an $\mathrm{ABI}$ Prism 3130 XL sequencer, with data collection software version 3.0.

Sequencing by Sanger method and phylogenetic analysis Samples were considered PCR positive if a PCR product of approximately $1030 \mathrm{bp}$ for the whole ITS region was obtained; ITS, ITS1, ITS2 and ITS2 (generic primers) were all amplified separately. PCR fragments were sequenced in both directions to assure sequence accuracy. DNA sequences were edited using the Sequencher ${ }^{\circledR}$ sequence analysis software (version 5.3; Gene Codes Corporation, Ann Arbor, MI, USA) and deposited in GenBank under accession numbers KT438661-KT438681.

The 19 Georgian rDNA ITS1 and IT2 sequences were concatenated and manually aligned using MEGA v6 software [22]. ITS1 and ITS2 region boundaries for all sequences were derived from primer-delimited sequences. A total of 51 sequences included from BLAST searches against the NCBI nucleotide database were chosen based on high similarity score. Genetic distances between rDNA sequences were estimated using the MEGA v6 software [22]. The best fit model was determined using the ML method based on Akaike Information Criterion (AIC) and Bayesian Information Criterion (BIC) values implemented in MEGA v6 [22]. The Jukes-Cantor (JC) model [23] was recommended by both AIC and BIC. Non-uniformity of evolutionary rates among sites was modeled by using a discrete Gamma distribution $(+\mathrm{G})$. Phylogenetic analysis based on the nucleotide sequences of concatenated Leishmania ITS1 and ITS2 sequences was performed using Neighbor joining (NJ) and Maximum Likelihood (ML) algorithms performed in MEGA v6 software. The rate variation among sites was modelled with a gamma distribution (shape parameter $=1$ ) with partial gap deletion. The analysis involved 68 nucleotide sequences. The bootstrap method was used to assess branch support (1000 replicates). 
Table 2 Sample description used for phylogenetic analysis in this study

\begin{tabular}{|c|c|c|c|}
\hline WHO number & Origin & $\begin{array}{l}\text { ITS sequence } \\
\text { type }\end{array}$ & $\begin{array}{l}\text { Accession } \\
\text { number }\end{array}$ \\
\hline \multirow[t]{2}{*}{ MHOM/BR/74/PP75 } & Brazil & ITS & AJ000304 \\
\hline & Brazil & ITS2 & GU045591 \\
\hline MHOM/IN/71/LRC-L51a & India & ITS1 & AJ000290 \\
\hline MHOM/SD/75/LV139 & Sudan & ITS & AJ000291 \\
\hline MHOM/IN/80/DD8 & India & ITS & AJ000292 \\
\hline $\mathrm{MHOM} / \mathrm{SD} / 68 / 1 \mathrm{~S}$ & Sudan & ITS & AJ000293 \\
\hline MHOM/KE/84/NLB218 & Kenya & ITS & AJ000296 \\
\hline MHOM/KE/85/NLB323 & Kenya & ITS & AJ000297 \\
\hline MCAN/SD/00/LEM3946 & Sudan & ITS1/2 & AJ634356 \\
\hline $\mathrm{MHOM} / \mathrm{SD} / 93 / \mathrm{GE}$ & Sudan & ITS1/2 & AJ634357 \\
\hline MHOM/SD/97/LEM3429 & Sudan & ITS1/2 & AJ634358 \\
\hline MHOM/ET/OO/HUSSEN & Ethiopia & ITS1/2 & AJ634360 \\
\hline MHOM/SD/62/LRC-L61 & Sudan & ITS1/2 & AJ634365 \\
\hline MHOM/SD/93/35-band & Sudan & ITS1/2 & AJ634366 \\
\hline MHOM/ET/72/GEBRE1 & Ethiopia & ITS1/2 & AJ634367 \\
\hline MHOM/SD/93/338 & Sudan & ITS1/2 & AJ634368 \\
\hline MHOM/SD/93/9S & Sudan & ITS1/2 & AJ634372 \\
\hline MHOM/ET/67/HU3 & Ethiopia & ITS1/2 & AJ634373 \\
\hline MHOM/KE/83/NLB189 & Kenya & ITS1/2 & AJ634374 \\
\hline MHOM/IN/54/SC23 & India & ITS1/2 & AJ634375 \\
\hline MHOM/IN/OO/DEVI & India & ITS1/2 & AJ634376 \\
\hline MHOM/IN/96/THAK35 & India & ITS1/2 & AJ634377 \\
\hline \multirow[t]{4}{*}{ MHOM/IN/01/BHU20140 } & India & ITS1/2 & AJ634378 \\
\hline & & ITS1/2 & FJ753386 \\
\hline & & ITS1/2 & GU045589 \\
\hline & & ITS1/2 & GU045590 \\
\hline MHOM/CN/00/Wangjie1 & China & ITS & AJ000294 \\
\hline MHOM/SU/1984/MARZ/KRIM & Ukrain & ITS & AM157172 \\
\hline MHOM/IQ/1981/SUKKAR2 & Iran & ITS1 & AM901452 \\
\hline MHOM/FR/78/LEM75 & France & ITS1/2 & AJ634339 \\
\hline MHOM/FR/95/LPN114 & France & ITS1/2 & AJ634340 \\
\hline MHOM/ES/93/PM1 & Spain & ITS1/2 & AJ634341 \\
\hline MHOM/FR/97/LSL29 & France & ITS1/2 & AJ634342 \\
\hline MHOM/ES/86/BCN16 & Spain & ITS1/2 & AJ634343 \\
\hline MHOM/PT/00/IMT260 & Portugal & ITS1/2 & AJ634344 \\
\hline MHOM/CN/54/Peking & China & ITS1/2 & AJ634345 \\
\hline MCAN/FR/87/RM1 & France & ITS1/2 & AJ634346 \\
\hline MHOM/ES/88/LLM175 & Spain & ITS1/2 & AJ634347 \\
\hline MHOM/MT/85/BUCK & Malta & ITS1/2 & AJ634350 \\
\hline MHOM/FR/80/LEM189 & France & ITS1/2 & AJ634351 \\
\hline MHOM/ES/92/LLM373 & Spain & ITS1/2 & AJ634352 \\
\hline MHOM/IT/94/ISS1036 & Italy & ITS1/2 & AJ634353 \\
\hline MHOM/IT/93/ISS800 & Italy & ITS1/2 & AJ634354 \\
\hline
\end{tabular}

Table 2 Sample description used for phylogenetic analysis in this study (Continued)

\begin{tabular}{llll}
\hline MHOM/SD/93/597-2 & Sudan & ITS1/2 & AJ634364 \\
MHOM/SD/82/GILANI & Sudan & ITS1/2 & AJ634369 \\
MHOM/SD/93/452BM & Sudan & ITS1/2 & AJ634371 \\
MHOM/TN/80/IPT1 & Tunisia & ITS & AJ000289 \\
& India & ITS1/2 & FJ948458 \\
MHOM/ET/72/L100 & Ethiopia & ITS1/2 & GQ920674 \\
\hline
\end{tabular}

\section{Statistical data analysis}

Data analysis was performed by using SPSS software version 20 (IBM), which was used to determine the statistical significance of differences between the groups by using Pearson's chi-squared test. A $P$ value of $<0.05$ was considered statistically significant.

\section{Results}

Prevalence of leishmaniasis in the human populations of Kakheti region

Seven individuals aged 3 to 56 years old were positive in the rK39 tests (average age 22.7, median age 9 years old). The majority of the human subjects (5/7) resided in Kvareli district. Of the seven patients, six were newly confirmed cases and one (aged 56) had previously been treated for relapse after treatment with liposomal amphotericin B (AmBisome ${ }^{\circ}$ ). Four of the six newly confirmed cases were asymptomatic while two displayed mild symptoms including fever and anemia. Subsequently, all six patients underwent a full course of treatment with an increased dose of AmBisome at the Institute of Medical Parasitology and Tropical Medicine, Tbilisi, making a full clinical recovery.

\section{Infection in canines}

Seropositive dogs were found in every settlement of both foci enrolled in the study. The test results shows that the prevalence of seropositive dogs in Kvareli District is significantly higher $(19.5 \%$; 64/329) 272 than in Sagarejo district $\left(11.4 \%\right.$; 31/271) $\left(\chi^{2}=7.301, d f=1, P=0.0069\right)$. The highest rates of canine seropositivity were $37.3 \%$ $(19 / 51)$ and $36.4 \%(20 / 55)$, detected in two villages of Kvareli District, Almati and Sabue, which are located within $2 \mathrm{~km}$ of each other (Fig. 1a). Dogs were grouped by their size (large, medium, and small breeds) and by age ( $\leq 1.5$ years; $1.5-5$ years; $\geq 5$ years old). There was no significant correlation between seropositivity and either the size of breed (Table 3) or sex of the dogs $\left(\chi^{2}=2.337, d f=1, P=0.126\right)$. However, seroprevalence was significantly higher in older dogs $\geq 1.5$ compared to dogs under 1.5 years of age $\left(\chi^{2}=19.368, d f=1, P<0.0001\right)$; interestingly, seroprevalence did not further increase in dogs $>5$ years age compared to those between 1.5 and 
Table $3 \mathrm{VL}$ seroprevalence in dogs categorized by breed and age

\begin{tabular}{llllllllllllll}
\hline Breeds & Small & \multicolumn{10}{c}{ Medium } & \multicolumn{10}{c}{ Large } \\
\hline Age & $\leq 1.5$ & $1.5-5$ & $>5$ & Total & $\leq 1.5$ & $1.5-5$ & $>5$ & Total & $\leq 1.5$ & $1.5-5$ & $>5$ & Total & Grand total \\
Total & 82 & 104 & 48 & 234 & 76 & 121 & 48 & 245 & 46 & 56 & 19 & 121 & 600 \\
Positive & 8 & 18 & 9 & 35 & 3 & 30 & 12 & 45 & 2 & 9 & 4 & 15 & 95 \\
$(\%)$ & 9.8 & 17.3 & 18.8 & 15 & 3.9 & 24.8 & 25.0 & 19 & 4.3 & 16.1 & 21.1 & 13 & 15.8 \\
\hline
\end{tabular}

No statistical association was found between seroprevalence and size of breed $\operatorname{VL}\left(X^{2}=2.337, d f=1, P=0.126\right)$

5 years old (Table 4) $\left(\chi^{2}=0.049, d f=1, \quad P=0.8256\right)$ (Table 4).

\section{Identification of Leishmania vectors}

To expand our previous surveys in Tbilisi and Kutaisi [8] we collected specimens of Phlebotomus in Kvareli and Sagarejo districts. In Kvareli we identified P. balcanicus, $P$. kandelakii and $P$. sergenti but only two of these species were found to be present in Sagarejo District ( $P$. balcanicus and P. kandelakii). All collected female sand flies were tested for Leishmania parasites by nested polymerase chain reaction (Ln-PCR). Two Phlebotomus flies, both $P$. balcanicus from Kvareli District, were PCR positive: $2.6 \%$ out of 78 female sand flies collected in the district (Table 5). No infected sand flies were found in the sample collected in Sagarejo District. In Kvareli District the most abundant species was P. balcanicus (29/ 78); in Sagarejo District P. kandelakii was the most abundant (27/39; Table 5).

\section{Genetic relationships}

Phylogenetic analysis of the ITS1/2 sequences derived from Georgian isolates showed close genetic association with the ITS1/2 sequences of representative isolates within the $L$. donovani complex. A single monophyletic subgroup was observed that comprised a distinct set of isolates (Group I). $\mathrm{NJ}$ and ML trees resolved eight of the 19 Georgian isolates into a single monophyletic subgroup, arbitrarily designated I, with significant bootstrap support (83 and $86 \%$, respectively) (Fig. 2, Additional file 1: Figure S1). A second group (II) was comprised of three isolates associated together in all trees analyzed albeit with non-significant bootstrap

Table $4 \mathrm{VL}$ seroprevalence in dogs of the different age categories

\begin{tabular}{llll}
\hline Age (years) & $\leq 1.5$ & $1.5-5$ & $>5$ \\
Total dogs & 204 & 281 & 115 \\
Positive & 13 & 57 & 25 \\
Negative & 191 & 224 & 90 \\
Percent & 7.0 & 21 & 22 \\
$\begin{array}{l}\text { Chi square test (relative } \\
\text { to age } \leq 1.5 \text { ) }\end{array}$ & & $x^{2}=18.022$, & $x^{2}=15.178$, \\
& & $d f=1, P<0.0001$ & $d f=0.0001$ \\
\hline
\end{tabular}

Data shown are appended from Table 1, showing totals for age of all three size categories. There was no significant difference in seroprevalence between age categories $1.5-5$ and $>5\left(x^{2}=0.049, d f=1, P=0.8256\right)$ support (65 and $61 \%$, respectively, for the NJ and ML trees) (Fig. 2, Additional file 1: Figure S1). Both genetic groups showed alternate topological placement respective to alternate phylogenetic algorithms. Although high bootstrap support was not obtained for the Group II Georgian isolates, they alone share an A28G variation in the poly-A tract of ITS1 not found in any of the other Georgian isolates, or in fact in any Leishmania strain sequenced to date (Additional file 2: Figure S2). In addition, these three isolates are distinguished from other Georgian isolates by sharing a single A insertion at position 34 that is also present in some $L$. infantum and $L$. donovani strains from other geographical locations.

NJ analysis distinguishes a single assemblage for all Georgian isolates with the exception of the human isolate from Tskhinvali, although bootstrap support was not significant under the best fit evolutionary model used (Fig. 2). This sample was isolated from a 15-month old male patient who had never traveled outside his district, demonstrating local transmission of the strain. In contrast, ML analysis indicated a paraphyletic relationship among Georgian isolates that includes the monophyletic subgroup arbitrarily designated here as Group I, which was also robustly supported in the NJ tree topology (Additional file 1: Figure S1). Group I is comprised of a total of eight human and canine isolates including representatives from Tbilisi, Sagarejo, Rustavi, Kvareli, Bolnisi and Teleti $(B S=81)$, showing that this genotype is geographically widespread in Eastern Georgia and may have a shared common ancestor. The three genetically similar (but unique compared to all other isolates) strains of Group 2 had all been isolated in Tbilisi (Group II) and this genotype has not been observed elsewhere in Georgia.

We noted seven arbitrary diversity regions (DR) designated DR1-7 among the combined ITS sequences analyzed (Additional file 2: Figure S2). Nucleotide variations comprised single nucleotide polymorphisms (SNPs), insertion/ deletions (InDels) and microsatellite copy number variations that are consistent with those previously reported for the donovani/infantum complex (Additional file 2: Figure S2, Additional file 3 - alignment file).

\section{Discussion}

We have recently published a survey of Leishmania infection in Tbilisi and in Kutaisi, a fairly large city in Central 
Table 5 Phlebotomus species identified in Kvareli District and Sagarejo District

\begin{tabular}{|c|c|c|c|c|c|c|c|c|}
\hline \multirow[t]{2}{*}{ Species } & \multicolumn{4}{|c|}{ Kvareli District } & \multicolumn{4}{|c|}{ Sagarejo District } \\
\hline & Male & Female & Positive & $\%$ of female & Male & Female & Positive & $\%$ of female \\
\hline P. (Adlerius) balcanicus & 24 & 29 & 2 & 6.9 & 10 & 9 & 0 & 0.0 \\
\hline P. (Paraphlebotomus) sergenti & 14 & 22 & 0 & 0 & 0 & 0 & 0 & 0.0 \\
\hline P. (Larroussius) kandelakii & 46 & 27 & 0 & 0 & 23 & 27 & 0 & 0.0 \\
\hline Total & 84 & 78 & 2 & 2.6 & 33 & 36 & 0 & 0.0 \\
\hline
\end{tabular}

Each female sand fly was tested and examined for Leishmania parasites microscopically and by PCR; both the number and percentage of Leishmania-positive flies are listed

Georgia [8]. The study addressed infection rates in Phlebotomus sand flies, canines and humans, and found particularly high incidence in the capital, but also transmission by infected vectors in Kutaisi. We tentatively concluded that leishmaniasis was spreading westward in the country, as the disease had not previously been reported as far west as the Kutaisi area, although it was noted that several different subspecies of Phlebotomus were identified compared to the capital. Historically, however, leishmaniasis has been much more prevalent in the east of the country, including Tbilisi. Indeed, there has been a recent surge in reported cases from the Kakheti region, east of the capital, which borders Azerbaijan and the Russian Federation. Between 2007 and 2014, 190 clinical cases of VL were reported in the Kakheti region, compared to just three in 2003 and nine in 2004 (Fig. 3). We thus decided to investigate two Kakhetian districts, Kvareli and Sagarejo, that reported relatively high incidence, of 21 and 26 cases, respectively, in 2007-2012 (41 \% of reported cases in Kakheti); previously only sporadic cases (less than one per year) had been reported from these areas. It must be stressed that these statistics reflect purely passive case-finding, i.e. patients presenting themselves with clinical symptoms, and correctly diagnosed with VL. Here, we report an active survey of human, canine and phlebotomine hosts in these districts to identify infections in the active foci and isolate DNA for genotyping. In order to maximize the number of (different) strains identified, surveys were performed in neighborhoods from which clinical cases had been reported, but diversity was maintained by sampling a maximum of three humans per household. Seven new human sub-clinical cases, with at most mild symptoms, were thus identified, out of 513 individuals screened. This confirms that (i) active case finding is necessary to avoid further increases in advanced clinical VL, and (ii) as reported for other regions including southern European countries, asymptomatic carriers contribute to the transmission cycle. Even more worrying, the incidence among dogs, especially over 1.5 years of age, was over $20 \%$. No doubt this contributes to the relatively high infection rate in sand flies that we observed in the same region $(2.6 \%$ of females double that of Kutaisi and similar to Tbilisi [8].

Trapping of Phlebotomus sand flies allowed the identification of potential vector species that actually carry
Leishmania parasites, and the isolation of DNA from those protozoans. The most prevalent sand fly species in both Kakhetian districts was $P$. kandelakii, which we previously found highly abundant in western Tbilisi [8], but not in Kutaisi. Phlebotomus balcanicus was also found in both districts, which was also observed in all Tbilisi districts and was the most prevalent species in Kutaisi. Finally, we observed some $P$. sergenti in the Kvareli District but not in Sagarejo although we had previously found it in both Tbilisi and Kutaisi [8]. These findings show that a number of Phlebotomus species are distributed through most of the country, whereas some appear to have a more local distribution (e.g. P. wenyoni in western Tbilisi [8]). Combining the previous Kutaisi/ Tbilisi study [8] with the current survey, only P. kandelakii $(n=17)$ and P. balcanicus $(n=5)$ have been found to be infected with Leishmania parasites anywhere in Georgia. Nevertheless large-scale surveys would be necessary to authoritatively confirm that these two species are the only VL vectors in the country.

Malaria control efforts in eastern Georgia in the 1960s included massive spraying campaigns with the insecticide dichlorodiphenyltrichloroethane (DDT) [8], which is believed to have also caused a significant reduction in the sand fly population, as during the next 40 years, until the 1990s, only sporadic VL cases were registered, and only in the extreme eastern part of the country. The existence of active VL foci in border region with Azerbaijan, however, may be facilitating the re-emergence of VL in Kakheti region [9].

We performed the first genotyping of Leishmania isolates in the Caucasus region, reporting here ITS-based molecular patterns in L. donovani complex samples originating from different geographical areas of eastern Georgia. The distinguishing residues observed in DR 6 and 7 (ITS-2) are entirely unique to the Georgian (and one Azerbaijani) strains reported here, and are not shared by other international isolates currently represented in the GenBank database. Future studies are needed to determine the population structure of Leishmania in Georgia in greater detail using additional markers, as well as to explore the prevalence and diversity of major genotypes. The molecular data presented here illustrate that in Tbilisi and other VL foci of 


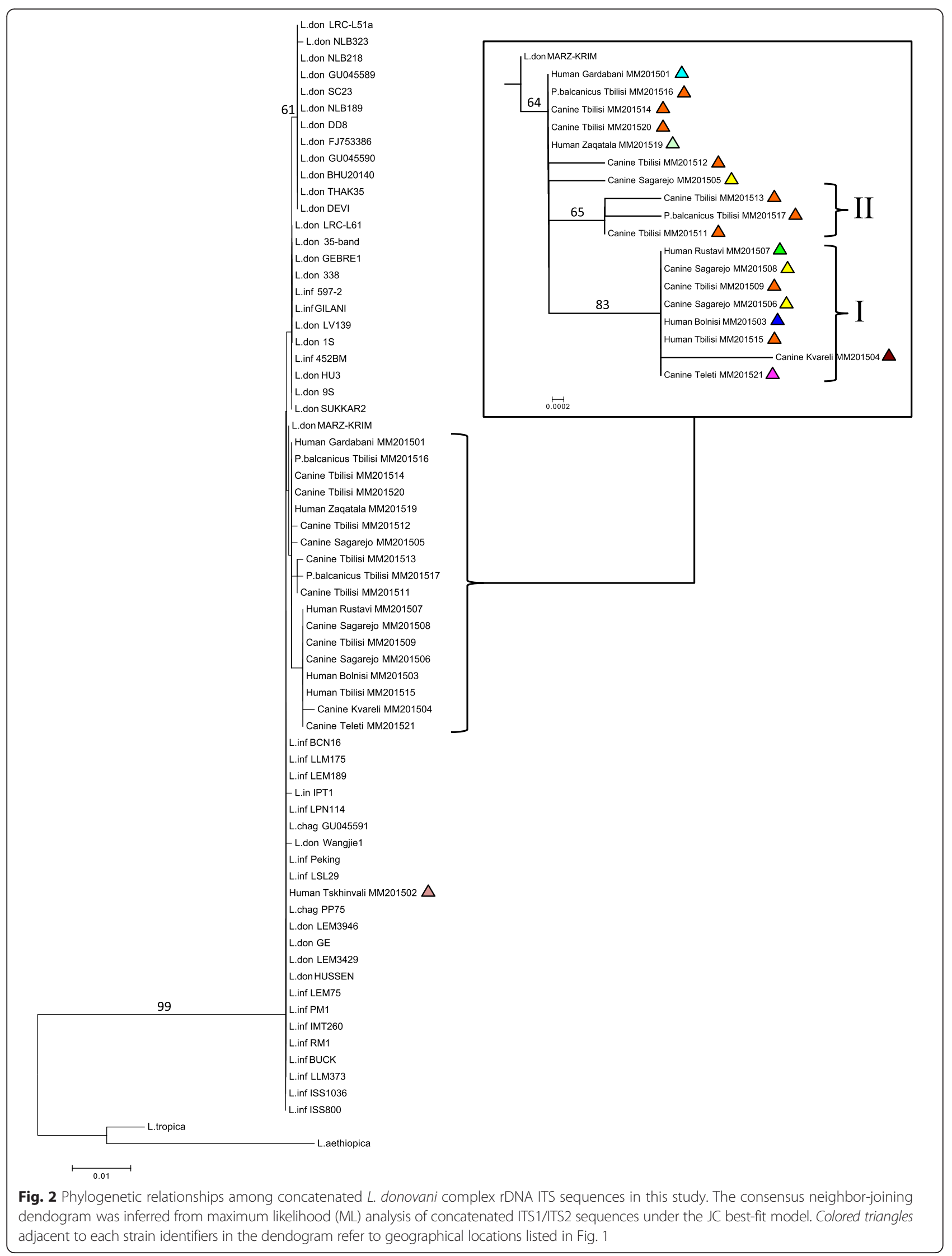




\section{reported cases of VL in the 8 districts} of the Katheti region

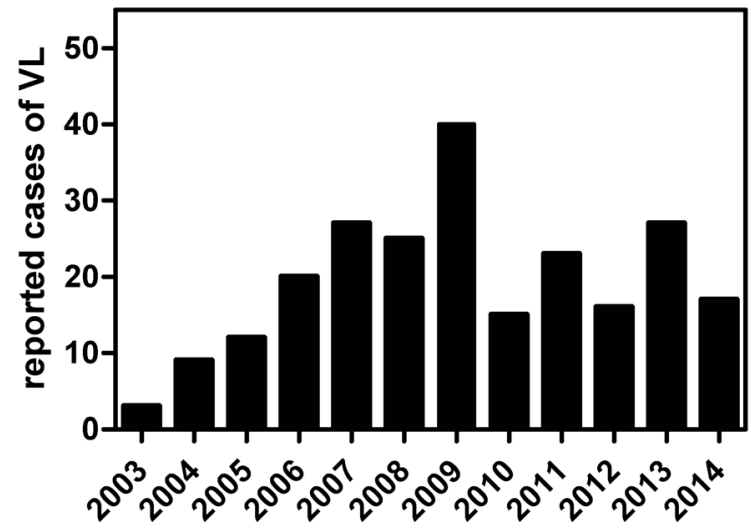

Fig. 3 Dynamics of $V L$ cases during the 12 years (from 2003 up to 2014) by years in Kakheti region

Georgia, genetically diverse Leishmania subtypes of the L. donovani complex are likely responsible for both human and canine leishmaniasis. Our data revealed preliminary insights into the genetic structure of L. donovani complex strains currently circulating in Georgia and demonstrate the utility of ITS-based Leishmania detection in the resource-limited country of Georgia. An expanded genetic interrogation using additional, higher resolution markers may provide deeper phylogenetic signal and will facilitate greater resolution of the genetic relationships within the $L$. donovani complex in the Caucasus.

\section{Conclusions}

In conclusion, this study confirms that VL remains the most serious vector-borne infection in Georgia, particularly affecting younger children and infants. The high incidence in canines is likely to keep the transmission levels high, as almost all households in rural Georgia keep dogs, as do many in the cities; furthermore, there are many stray dogs that appear to help spread the disease to new areas. In order to break the transmission cycle, vector control would appear to be the most effective option, given the already very high prevalence in domestic and stray dogs, and the absence of affordable, effective treatment for canine leishmaniasis. Although five Phlebotomus sand fly species have been identified in the country, to date only two have been found to carry Leishmania parasites and it is on these species, particularly, that control measures must focus; further research on their prevalence in other parts of the country will be necessary. Finally, we report the first ITS-based detection of Leishmania strains in the Caucasus region and show that these strains are part of the $L$. donovani complex with selected genotypes that are unique to the region. Such data provide further insights into the genetic structure of this pathogen in Eurasia and may inform future comparative studies focused on delineating regional subtypes and any impact on the epidemiology of disease.

\section{Additional files}

Additional file 1: Figure S1. Consensus maximum likelihood (ML) dendogram inferred from concatenated $L$. donovani complex rDNA ITS sequences under the JC best-fit model. (PDF $49 \mathrm{~kb}$ )

Additional file 2: Figure S2. Partial alignment illustration of major regions of ITS1/2 sequence diversity. (PDF $118 \mathrm{~kb}$ )

Additional file 3: Full alignment. FASTA file of concatenated $L$. donovani complex ITS sequences included in this study. (FASTA $76 \mathrm{~kb}$ )

\section{Abbreviations}

AIC: Akaike Information Criterion; BIC: Bayesian Information Criterion; DR: diversity region; ITS: Internal transcribed spacer; JC: Jukes-Cantor; ML: maximum likelihood; NJ: neighbor joining; NNN: Novy-MacNeal-Nicolle medium; SNP's: single nucleotide polymorphisms.

\section{Competing interests}

The authors declare that they have no competing interests.

\section{Authors' contributions}

Conceived and designed the experiments: GB, HPdK, G.CH, EA, PI, DTS, IK, IK, Performed the experiments: GB, EC, JF, MM, GCH, NK, KS, IM. Analyzed the data: GB, JF, HPdK. Contributed reagents/materials/analysis tools: GB, IK, GCH, HPdK. Wrote the paper: GB, JF, HPdK, MM, EC. All authors read and approved the final version of the manuscript.

\section{Author details}

${ }^{1}$ National Center for Disease Control and Public Health of Georgia, 9 M. Asatiani Str. 0186, Tbilisi, Georgia. ${ }^{2}$ llia State University, Tbilisi, Georgia. ${ }^{3}$ Farlow Scientific Consulting Company, Lewiston, UT, USA. ${ }^{4}$ Institute of Infection, Immunity and Inflammation, College of Medical, Veterinary and Life Sciences, University of Glasgow, Glasgow G43 2DX, UK. ${ }^{5}$ Unit of Leishmaniasis and Chagas Disease, WHO Collaborating Centre for Leishmaniasis, National Center for Microbiology, Institute of Health Carlos III, Madrid, Spain. ${ }^{6}$ S. Virsaladze Research Institute of Medical Parasitology and Tropical Medicine, Tbilisi, Georgia.

Received: 9 February 2016 Accepted: 2 May 2016

Published online: 13 May 2016

\section{References}

1. WHO. Technical Report Series 949: Control of the leishmaniases: report of a meeting of the WHO Expert Committee on the Control of Leishmaniases. Geneva: World Health Organization; 2010.

2. Alvar J, Velez ID, Bern C, Herrero M, Desjeux P, Cano J, et al. Leishmaniasis worldwide and global estimates of its incidence. PLoS One. 2012;7, e35671.

3. Alvar J, Aparicio P, Aseffa A, Den Boer M, Cañavate C, Dedet JP, et al. The relationship between leishmaniasis and AIDS: the second 10 years. Clin Microbiol Rev. 2008;21:334-59.

4. Ready PD. Leishmaniasis emergence in Europe. Euro Surveill. 2010;15:19505.

5. Pennisi MG, Cardoso L. Leishmaniosis of companion animals in Europe: an update. Vet Parasitol. 2015;208:35-47.

6. Poeppl W, Herkner H, Tobudic S, Faas A, Auer H, Mooseder G, et al. Seroprevalence and asymptomatic carriage of Leishmania spp. in Austria, a non-endemic European country. Clin Microbiol Infect. 2013;19:572-7.

7. El Baidouri F, Diancourt L, Berry V, Chevenet F, Pratlong F, Marty P, Ravel C. Genetic structure and evolution of the Leishmania genus in Africa and Eurasia: what does MLSA tell us. PLoS Negl Trop Dis. 2013;7(6), e2255. 
8. Babuadze G, Alvar J, Argaw D, De Koning HP, losava M, Kekelidze M, et al. Epidemiology of visceral leishmaniasis in Georgia. PLoS Negl Trop Dis. 2014;8(3), e2725.

9. Strelkova MV, Ponirovsky EN, Morozov EN, Zhirenkina EN, Razakov SA, Kovalenko DA, et al. A narrative review of visceral leishmaniasis in Armenia, Azerbaijan, Georgia, Kazakhstan, Kyrgyzstan, Tajikistan, Turkmenistan, Uzbekistan, the Crimean Peninsula and Southern Russia. Parasit Vectors. 2015;8:330.

10. Maruashvili GM. [About types of visceral leishmaniasis foci]. Med Parasitol (Moscow). 1961;30:188-90 [In Russian].

11. Bardjadze BG. [Some questions about visceral leishmaniasis in Georgia]. Sabchota Medicina. 1966;2:28-32 [In Georgian].

12. Kuhls K, Mauricio IL, Pratlong F, Presber W, Schönian G. Analysis of ribosomal DNA internal transcribed spacer sequences of the Leishmania donovani complex. Microbes Infect. 2005;7:1224-34.

13. Tellevik MG, Muller KE, Løkken KR, Nerland AH. Detection of a broad range of Leishmania species and determination of parasite load of infected mouse by real-time PCR targeting the arginine permease gene AAP3. Acta Trop. 2014;137:99-104

14. el Tai NO, Osman OF, el Fari M, Presber W, Schönian G. Genetic heterogeneity of ribosomal internal transcribed spacer in clinical samples of Leishmania donovani spotted on filter paper as revealed by single-strand conformation polymorphisms and sequencing. Trans R Soc Trop Med Hyg. 2000;94:575-9.

15. Marfurt J, Niederwieser I, Makia ND, Beck HP, Felger I. Diagnostic genotyping of Old and New World Leishmania species by PCR-RFLP. Diagn Microbiol Infect Dis. 2003;46:115-24.

16. Lewin S, Schönian G, Oskam N, el Tai L, Bastien P, Presber W. Strain typing in Leishmania donovani by using sequence-confirmed amplified region analysis (SCAR). Int J Parasitol. 2002;32:1267-76.

17. Maroli M, Krasnonos L, Gafurov I. Epidemiological and entomological survey in a focus of visceral leishmaniasis in Pap district (Fergana Valley) of Namangan region, Uzbekistan. Acta Trop. 2001;80:223-8.

18. Sánchez-García L, Berzunza-Cruz M, Becker-Fauser I, Rebollar-Téllez EA. Sand flies naturally infected by Leishmania (L.) mexicana in the peri-urban area of Chetumal city, Quintana Roo, México. Trans R Soc Trop Med Hyg. 2010;104:406-11.

19. Ferroglio E, Maroli M, Gastaldo S, Mignone W, Rossi L. Canine leishmaniasis, Italy. Emerg Infect Dis. 2005;11:1617-20.

20. Martín-Sánchez J, Morales-Yuste M, Acedo-Sánchez C, Barón S, Díaz V, Morillas-Márquez F. Canine leishmaniasis in southeastern Spain. Emerg Infect Dis. 2009;15:795-8.

21. Almeida ME, Steurer FJ, Koru O, Herwaldt BL, Pieniazek NJ, da Silva AJ, Identification of Leishmania spp. by molecular amplification and DNA sequencing analysis of a fragment of rRNA internal transcribed spacer 2. J Clin Microbiol. 2011;49:3143-9.

22. Tamura K, Stecher G, Peterson D, Filipski A, Kumar S. MEGA6: molecular evolutionary genetics analysis version 6.0. Mol Biol Evol. 2013:30:2725-9.

23. Jukes TH, Cantor CR. Evolution of protein molecules. In: Munro HN, editor. Mammalian protein metabolism. New York: Academic Press; 1969. p. 21-132.

\section{Submit your next manuscript to BioMed Central and we will help you at every step:}

- We accept pre-submission inquiries

- Our selector tool helps you to find the most relevant journal

- We provide round the clock customer support

- Convenient online submission

- Thorough peer review

- Inclusion in PubMed and all major indexing services

- Maximum visibility for your research

Submit your manuscript at www.biomedcentral.com/submit
Biomed Central 